\title{
Population Density Estimates and Growth Rates of Eleutherodactylus coqui in Hawaii
}

\author{
Karen H. Beard, ${ }^{1,2}$ Robert Al-Chokhachy, ${ }^{3}$ Nathania C. Tuttle, ${ }^{1}$ and Eric M. O’Neill ${ }^{4}$ \\ ${ }^{1}$ Department of Wildland Resources and the Ecology Center, Utah State University, Logan, Utah 84322-5230 USA \\ ${ }^{3}$ Department of Watershed Sciences, Utah State University, Logan, Utah 84322-5210 USA \\ ${ }^{4}$ Department of Biology, Utah State University, Logan, Utah 84322-5305 USA
}

\begin{abstract}
Aвstract.-The Puerto Rican terrestrial frog (Eleutherodactylus coqui) has received considerable attention in Hawaii because of its rapid spread, loud mating calls, and its potential threat to native species. Thus far, its invasion potential on the Island of Hawaii remains poorly understood. Critical components for determining this potential are robust estimates of abundance and vital rates across habitat types. To address this lack of information, we used mark-recapture methods to estimate E. coqui survival and abundance, determine growth rates of adult male and female frogs, and relate densities to elevation, snout-vent length (SVL), habitat structure, and invertebrate abundance. Mean adult E. coqui density across eight sites was $62 \pm$ 12 adults $/ 100 \mathrm{~m}^{2}$ and ranged from $6-138$ adults $/ 100 \mathrm{~m}^{2}$. Our three-year mean adult density estimates were three times greater at three of our study sites $\left(100\right.$ adults $\left./ 100 \mathrm{~m}^{2}\right)$ than the highest long-term estimates from Puerto Rico $\left(33\right.$ adults $\left./ 100 \mathrm{~m}^{2}\right)$. Mean individual growth rates were $0.0078 \mathrm{~mm} / \mathrm{day}( \pm 0.007 \mathrm{SD}, N=87)$ for males and $0.0097 \mathrm{~mm} /$ day $( \pm 0.009 \mathrm{SD}, N=11)$ for females. Frogs of similar size were found to be growing slower in Hawaii than Puerto Rico. We found no relationship between elevation and E. coqui density or elevation and SVL or between invertebrate abundance and $E$. coqui density. However, there was a positive relationship between understory structure and $E$. coqui density. This relationship suggests that removing understory structure could reduce E. coqui densities, although other potential implications of this management treatment should be considered.
\end{abstract}

The global distribution of the Puerto Rican terrestrial frog, Eleutherodactylus coqui, is expanding. Eleutherodactylus coqui was introduced to Hawaii in the late 1980s probably via the horticulture trade (Kraus et al., 1999). In 1998, there were eight known populations on the Island of Hawaii (Kraus et al., 1999). Over the next three years, it had spread to over 250 sites throughout the Hawaiian Islands (Kraus and Campbell, 2002). Because of eradication efforts on Maui, Oahu, and Kauai, E. coqui are now mostly concentrated in lowland $(0-1,100 \mathrm{~m})$ forests on the Island of Hawaii (Beard and Pitt, 2005). E. coqui is considered an invasive pest because it threatens private property value because of its loud mating calls and floriculture and nursery industries due to decreased sales and rejected shipments (Kraus and Campbell, 2002).

The invasion is of ecological concern because E. coqui is able to reach extremely high densities. In its native Puerto Rico, long-term studies of adult $E$. coqui densities range from 1-33 adults per $100 \mathrm{~m}^{2}$ (Stewart and Pough, 1983; Woolbright, 1991; Stewart and Woolbright, 1996; Fogarty and Vilella, 2002). Thus far, one study

\footnotetext{
${ }^{2}$ Corresponding Author. E-mail: karen.beard@ usu.edu
}

conducted in Hawaii has estimated population densities for two sites on the southeast side of the Island of Hawaii (Woolbright et al., 2006) and found that E. coqui densities can be three times as great as mean long-term densities in Puerto Rico (up to 118 adults per $100 \mathrm{~m}^{2}$ ). In addition, because E. coqui is insectivorous, there is concern that it could prey upon native invertebrates and compete with native birds, many of which are insectivorous (Kraus et al., 1999).

Thus, there is a need to control or eradicate $E$. coqui populations (Kraus and Campbell, 2002). Identifying factors that limit E. coqui in Hawaii could offer mechanisms for more efficient control. Prior research in Puerto Rico has suggested that habitat structure, the availability of retreat and nest sites, is the primary factor limiting E. coqui populations (Stewart and Pough, 1983; Woolbright, 1991). However, results from small-scale enclosure experiments and large-scale monitoring of invertebrates have demonstrated that $E$. coqui reduce invertebrates at small-scales and have a positive relationship with invertebrates at landscapescales, providing support for the hypothesis that they can also be prey-limited (Beard, 2001).

Because E. coqui is an invasive pest and the focus of control efforts, robust estimates of abundance and vital rates across habitat types 


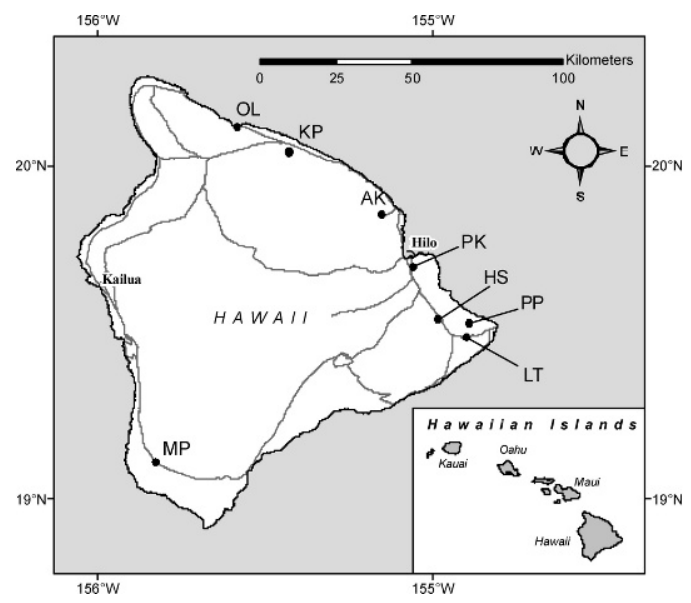

FIG. 1. Locations of eight study sites for Eleutherodactylus coqui mark-recapture analyses. AK = Akaka Falls State Park (year introduced: 2001; elevation: $405 \mathrm{~m}), \mathrm{HS}=$ Humane Society $(1998 ; 135 \mathrm{~m}), \mathrm{KP}=$ Kalopa State Park (1999; 610 m), LT = Lava Tree State Park (1996; 181 m), MP = Manuka State Park/Natural Area Reserve (2000; $556 \mathrm{~m}), \mathrm{OL}=$ Waipio Overlook (2000; 303 m), Puainako Street/Safeway = PK (1998; $45 \mathrm{~m})$, and PP = Hawaiian Paradise Park (2000; $50 \mathrm{~m})$. Year introduced from USDA/Wildlife Services hotline.

could assist management efforts. This study was designed to determine population abundances and vital rates of E. coqui, such as survival rate estimates, capture/recapture probabilities, and individual growth rates, for eight established plots on the Island of Hawaii. In addition, we relate population densities to elevation, habitat structure, and prey availability to identify factors that may limit E. coqui.

\section{Materials And Methods}

Study Areas.-Research was conducted in eight tropical forest sites on the Island of Hawaii (Fig. 1). These sites were selected because they had established E. coqui populations and because of their diversity in forest-type, climate, and geological history. Eleutherodactylus coqui populations were established in different years at each site (Fig. 1). Dominant overstory trees differed across sites and included Cecropia obtusifolia (sites abbreviated after species name have this species as a dominant: HS), Falcataria mollucana (LT), Melaleuca quinquenervia (WO), Metrosideros polymorpha (AK, KP, and MP), and Psidium cattleianum (PK, and PP). Dominant understory plants also differed across sites and included: Archontophoenix alexandrae (HS), Clidemia hirta (LT), Monstera deliciosa (AK), Microlepia strigosa (KP), P. cattleianum (MP, PK, and WO), and Syzygium jambos (PP). Mean annual temperature across study sites ranged from $18-23^{\circ} \mathrm{C}$
(Nullet and Sanderson, 1993), whereas mean precipitation ranged from 1,000-6,000 mm/year (Price, 1983). Substrate age across sites ranged from 200-10,000 years old (Trusdell et al., 2005).

Sampling Design and Surveys.-A $20 \times 20-\mathrm{m}$ plot was established at each site. The original objective was to collect mark-recapture data for seven sites during the fall of 2004, 2005, and 2006. However, one site (Paradise Park) was developed in 2005; thus, so we only have one year of data for Paradise Park (2004). This site was replaced with Kalopa State Park, where we have two years of data (2005 and 2006).

We used standardized methods for markrecapture analysis of this species (Woolbright, 2005). Surveys were conducted between September and November annually for three years. We searched one plot each night between time of full darkness and midnight. Frog surveys were conducted in each of four adjoining $5 \times$ 20-m transect subplots for $15 \mathrm{~min}$, for a total search time within the $20 \times 20-\mathrm{m}$ plot of $60 \mathrm{~min}$, not including handling time. Three researchers conducted the surveys each night; two researchers searched for and handled frogs while one researcher followed and recorded data. We began the first survey in the first transect of each plot, and alternated between starting in the first or last transect during subsequent nights. Each plot was searched for 5-9 consecutive nights until we obtained a $60 \%$ recapture rate for the sampling period.

When frogs were captured, we measured and marked only adult frogs ( $\geq 25 \mathrm{~mm}$ snout-vent length, SVL, [Woolbright, 2005]). We used SVL as the basic measure of body size throughout this study. We measured SVL to the nearest $0.1 \mathrm{~mm}$ with dial calipers and marked frogs by clipping a total of 1-4 toes (one clip per foot) in unique combinations. We categorized adults as either male, when they were observed calling or vocal sacs were obvious, or female, when they had ova in any stage of development visible through their semitransparent body wall. To be conservative, we considered sex for all other individuals undeterminable. We did not mark juveniles and subadults (6-24 mm SVL), hereafter preadults, because toes are too small for clipping (Woolbright, 2005). Because preadults are important in determining overall density, we counted the number of preadults observed in a plot each night.

Just prior to dusk, in May 2004, we collected invertebrates from four trees representing the dominant understory species at each site using beating traps. We also collected leaf litter invertebrates from $4-0.25 \times 0.25 \mathrm{~m}$ areas on the forest floor in each plot and extracted them using Berlese funnels. After $1900 \mathrm{~h}$, we collected aerial invertebrates for $3 \mathrm{~h}$ adjacent to each plot 
using a black light. To estimate invertebrate abundance in each plot, we averaged replicates of the beating trap samples and replicates of the leaf litter invertebrate samples and added those averages to the black light samples. More information on how these invertebrates were collected and identified is described in Beard (2007).

In September 2006, understory density was estimated for each plot using Nudds method (1977). A $0.5 \mathrm{~m} \times 2 \mathrm{~m}$ coverboard with a checkerboard pattern of 100 alternating squares was placed in the center of each plot. Photographs were taken $5 \mathrm{~m}$ from the coverboard in each of the cardinal directions at $1 \mathrm{~m}$ and $2 \mathrm{~m}$ above the forest floor. We counted how many squares were visible and used the mean from the two heights and then the mean of the four cardinal directions to determine the percent coverboard covered for each plot. This gave us a relative measure of understory vegetative structure between 0 and $2 \mathrm{~m}$ above the forest floor.

Growth Rates.-Growth rates were determined in the field by measuring marked frogs. Because animals were individually marked, it was possible to make multiple measurements on the same individual over time. We calculated growth rate as the change in SVL divided by the number of days since the frog was last measured.

For comparison, we determined growth rates in the laboratory. We transported approximately 40 male and 30 female E. coqui from Hawaii to Logan, Utah, and housed frogs in breeding pairs in half of a $37.85-\mathrm{L}$ terrarium. These frogs were toe clipped using the system used to mark frogs in the field. Frogs were given retreat sites (15-cm PVC pipe) and one small potted plant of Pothos sp. Frogs were given both crickets and water ad libitum. Half the frogs were maintained at $19^{\circ} \mathrm{C}$ and half at $25^{\circ} \mathrm{C}$ with a $12: 12 \mathrm{~L}: \mathrm{D}$ cycle and $>90 \%$ humidity within the aquaria. We measured SVL when the frogs were collected and 10 months later and calculated growth rate as above.

Analyses.-We evaluated population density using closed capture models in Program MARK (White and Burnham, 1999). For the Kalopa and Paradise Park plots, where we collected fewer than three years of data, we used Huggins closed-capture models to estimate abundance. Under this approach, individual encounter histories are used to estimate both initial capture probability $(p)$, the probability that a previously marked frog is recaptured (recapture probability, $c)$, and population abundance $(\hat{\mathrm{N}})$. Additionally, individual covariates, and their effects, can be used in modeling $p$ and $c$ with Huggins closed-capture models, and we modeled the effects of the number of toe clips as an individual covariate on recapture probability and survival.

For all other plots, where we collected three years of data, we used a robust-design approach with Huggins closed-capture models. Robust design mark-recapture methods use a combination of closed-capture sampling for abundance estimates and open-mark-recapture vital rate analyses (Pollock 1982). Furthermore, we selected this approach because robust design models can reduce bias associated with the heterogeneous capture/recapture probabilities (Pollock 1982), which we have found often occur in $E$. coqui populations. This approach relies on using multiple sampling events over short time periods, where closure of population is assumed (i.e., no mortalities), and longer intervals, where losses are expected to occur, to estimate the probability of initial capture and recapture, survival rate $(S)$, emigration $\left(\gamma^{\prime \prime}\right)$, the probability of remaining outside the study area $\left(\gamma^{\prime}\right)$, and population size $(\hat{\mathrm{N}})$. For all robustdesign analyses, we assumed that emigration rates and immigration rates were random and modeled $\gamma^{\prime \prime}=\gamma^{\prime}$ (Kendall et al., 1997). For all analyses, we established a set of a priori models where we included sampling period and the number of toe clips as an individual covariate. Similar to Franklin et al. (2004), we first modeled those parameters of less biological interest to these analyses (e.g., $p, c, \gamma^{\prime}$, and $\gamma^{\prime \prime}$ ) and then maintained the model structure of these parameters with the lowest Akaike's information criterion value $\left(\mathrm{AIC}_{\mathrm{C}}\right.$ : bias-adjusted for small sample size) while modeling $S$.

To maximize the information gained within a multimodel approach, we used model averaging, where we used Akaike weights to compute a weighted estimate for apparent survival and capture probabilities (Burnham and Anderson, 1998). Under a model-averaging approach, models with different structures can be considered simultaneously; however, those models with larger Akaike weights will have greater influence on the overall, model-averaged estimates. For each model, we used the 95\% confidence intervals of the beta estimates (i.e., slope) to measure statistical significance for each parameter and considered differences among parameter estimates significant when confidence intervals did not overlap (Bradford et al., 2005). We report model-averaged estimates of $\hat{\mathrm{N}}$ and survival for each plot.

To obtain an estimate of total abundance and density (individuals $/ 100 \mathrm{~m}^{2} \pm 1 \mathrm{SE}$ ) for each sampling period, preadult numbers in plots were estimated as the product of the adult estimate and the ratio of preadult to adult counts, assuming that preadult and adult 
TABle 1. Population estimates ( $\pm \mathrm{SE}$ ) of adult Eleutherodactylus coqui (per $100 \mathrm{~m}^{2}$ ) across eight study sites on the Island of Hawaii from 2004-2006. Mean capture $(p)$ and recapture $(c)$ probabilities (range) and survivorship estimates $(S)( \pm \mathrm{SE})$, and the effect of toe clipping on recapture probabilities $(c)$ and survival estimates $(S)$. ns $=$ nonsignificant.

\begin{tabular}{|c|c|c|c|c|c|c|c|c|}
\hline \multirow[b]{2}{*}{ Site } & \multicolumn{3}{|c|}{ Population estimate } & \multirow{2}{*}{$\begin{array}{c}\text { Total } \\
\text { marked }\end{array}$} & \multirow[b]{2}{*}{$p / c^{*}$} & \multirow[b]{2}{*}{$S$} & \multirow{2}{*}{$\begin{array}{l}\text { Effect of toe } \\
\text { clips on } c\end{array}$} & \multirow{2}{*}{$\begin{array}{c}\text { Effect of toe } \\
\text { clips on } S\end{array}$} \\
\hline & 2004 & 2005 & 2006 & & & & & \\
\hline$\overline{\mathrm{AK}}$ & $63(6)$ & $52(5)$ & $39(4)$ & 360 & $0.13(0.04-0.24)$ & $n e^{+}$ & ns & ns \\
\hline HS & $72(4)$ & $72(4)$ & $87(5)$ & 607 & $0.19(0.09-0.29)$ & $0.47(0.35)$ & ns & ns \\
\hline LT & $133(9)$ & $100(7)$ & $102(11)$ & 824 & $0.17(0.11-0.24)$ & $0.13(0.01)$ & negative & ns \\
\hline $\mathrm{MP}$ & $138(30)$ & $54(4)$ & $13(2)$ & 289 & $0.15(0.005-0.40)$ & $0.24(0.11)$ & ns & negative \\
\hline $\mathrm{OL}$ & $21(4)$ & $14(2)$ & $25(1)$ & 170 & $0.25(0.08-0.45)$ & $0.10(0.04)$ & negative & ns \\
\hline PK & $53(7)$ & $57(7)$ & $75(5)$ & 411 & $0.11(0.03-0.23)$ & $0.32(0.22)$ & negative & ns \\
\hline PP & $94(8)$ & - & - & 216 & $0.16(0.09-0.22)$ & - & ns & - \\
\hline $\mathrm{KP}$ & - & $6(1)$ & - & 21 & $p=0.22(0.08) ; c=0.06(0.02)^{\dagger}$ & - & ns & - \\
\hline KP & - & - & $15(1)$ & 56 & $p=0.47(0.06) ; c=0.26(0.04)^{\dagger}$ & - & ns & - \\
\hline
\end{tabular}

${ }^{*}$ Top models suggested similar capture and recapture probabilities for all study sites except KP.

$\dagger$ Top models suggested different capture and recapture probabilities. SE values are shown as there was no time effect.

$\$ S$ not estimable for this plot.

probabilities of encounter by observers are similar (as in Woolbright, 1996, 2005).

All other statistical analyses were conducting using SAS Version 9.1.3 (2006). We conducted least-squares regression between elevation and density and SVL and between E. coqui density and invertebrate abundance and understory structure using PROC REG. Factorial ANOVAs were used in a completely randomized design to evaluate the fixed effects of site and sex and year, as appropriate, on the following response variables: SVL and growth rates. For the growth rate analysis, site was used as a random effect. When necessary to meet assumptions of normality and homogeneity of variance, data were log-transformed. All means comparison tests were conducted using the Tukey-Kramer procedure. Significant differences were accepted at $P<0.05$.

\section{RESULTS}

Mark-Recapture.-Between 2004 and 2006, we captured a total of 2,954 adult E. coqui in eight study plots over 120 nights of surveying. Of those frogs, 1,359 were identified as males, 106 were identified as females, and 1,489 were of indeterminate sex. Of these frogs, 986 (33\%) were recaptured at least once during the same sampling period (consecutive days within one year). There were 101 frogs $(7 \%)$ recaptured across years, with one frog detected in all three years.

We were unable to estimate parameters by sex because of the generally low capturerecapture rates, inability to delineate between sexes, and few females captured during this study within and across years (in part a function of our strict definition of female: gravid); thus, all parameter estimates (e.g., abundance) include males, females, and frogs of unknown sex.

Structure for the top models in most plots suggested capture probabilities did not differ from recapture probabilities (i.e., $p=c$ ), and estimates of capture-recapture varied across years and individual sample dates (Table 1; Appendix 1). Consistent with the similarities in model structure, mean capture-recapture probabilities were generally similar across plots (range: 0.11-0.25). In the Kalopa plot, however, where capture probabilities differed significantly from recapture probabilities, we found substantially higher capture probabilities and lower recapture probabilities than all other plots.

The effect of the number of toe clips on recapture rates varied across plots, with no significant effect in the Akaka Falls, Humane Society, Kalopa, Manuka, or Paradise Park plots, and a significant, negative effect in the Lava Tree, Puainako, and Waipio plots (Table 1).

Survival analyses over three years allowed for one estimate of annual survival for each site corresponding to the interval between 2004 and 2005. We found the lowest annual survival in the Waipio (0.10) and the highest annual survival in the Humane Society plot (0.47; Table 1). The number of toe clips had a significant, negative effect on E. coqui frog survival in the Manuka plot but did not have significant effects in any of the other plots.

Density.-Adult E. coqui density (individuals $\left.100 / \mathrm{m}^{2}\right)$ varied across years and plots during this time period (2004-2006; Table 1). We found the lowest adult density in Kalopa in both 2005 $(6 \pm 1$; mean \pm SE) and $2006(15 \pm 1)$ and the highest adult densities in Paradise Park (2004: 
TABLE 2. Maximum preadult counts per plot, mean daily preadult to adult counts, and total Eleutherodactylus coqui density for each site on the Island of Hawaii. Total density was calculated by multiplying the ratio of preadults to adults by the estimate of adults from Table 1, and adding this to the estimate of adults.

\begin{tabular}{|c|c|c|c|c|c|c|c|c|c|c|}
\hline \multirow[b]{2}{*}{ Site } & \multicolumn{3}{|c|}{ Maximum preadult counts } & \multicolumn{3}{|c|}{ Mean preadult : adult } & \multicolumn{4}{|c|}{ Total density (frogs $/ 100 \mathrm{~m}^{2}$ ) } \\
\hline & 2004 & 2005 & 2006 & 2004 & 2005 & 2006 & 2004 & 2005 & 2006 & Mean \\
\hline AK & 277 & 277 & 131 & 10.86 & 2.64 & 5.55 & 747 & 189 & 255 & 397 \\
\hline HS & 142 & 142 & 161 & 2.00 & 2.27 & 1.35 & 216 & 235 & 204 & 218 \\
\hline $\mathrm{KP}$ & - & 15 & 8 & - & 2.97 & 0.36 & - & 24 & 20 & 22 \\
\hline $\mathrm{LT}$ & 143 & 143 & 453 & 1.43 & 2.27 & 2.97 & 323 & 327 & 405 & 352 \\
\hline $\mathrm{MP}$ & 176 & 176 & 28 & 5.62 & 0.57 & 2.21 & 914 & 85 & 42 & $499^{*}$ \\
\hline $\mathrm{OL}$ & 6 & 6 & 21 & 0.24 & 1.17 & 0.20 & 26 & 31 & 30 & 29 \\
\hline PK & 45 & 45 & 39 & 1.84 & 1.27 & 2.05 & 151 & 129 & 229 & 170 \\
\hline $\mathrm{PP}$ & 157 & - & - & 2.76 & - & - & 353 & - & - & 353 \\
\hline
\end{tabular}

* Mean total density was calculated across years except for Manuka Natural Area Reserve where we excluded the last year due to repeated citric acid treatments to control the frogs.

$94 \pm 8$ ), Humane Society (mean: $77 \pm 5$ ), and Lava Tree (mean: $112 \pm 11$ ). Density of adults in Manuka was extremely high the first year it was sampled (2004: $138 \pm 30$ ).

Mean preadult to adult ratio averaged across years and the eight sites was $2.5: 1 \pm 1.7$ (SD) and ranged from 0.2-10.9 across sampling periods (Table 2). Mean total frog density, including preadults, and averaged across years for the eight sites was $255 \pm 174$ (SD) frogs/ $100 \mathrm{~m}^{2}$ and ranged from $20-914$ frogs $/ 100 \mathrm{~m}^{2}$ across sampling periods.

The relationship between total density and habitat structure was positive across study sites $\left(N=7, R^{2}=0.85, P<0.01\right.$; Fig. $\left.2 \mathrm{~A}\right)$. There was no relationship between invertebrate abundance and total density across study sites in $2004(N=$ 7, $R^{2}=0.45, P=0.10$; Fig. 2B).

Size and Growth Rates. - Frogs across the study sites varied in size $\left(F_{7,1385}=12.48, P<0.0001\right)$, and females were $21 \%$ larger than males $\left(F_{1,1385}\right.$ $=12.48, P<0.001$; Table 3). Even though recaptured frogs were removed from the analysis, frogs across sites were significantly larger each year than the previous year $\left(F_{2,1385}=5.42\right.$, $P=0.0045)$.

There was no relationship between total density and SVL across all study sites $(N=7$, $R^{2}=0.38, P=0.13$; Fig. 3A). However, if Kalopa is removed from the analysis, the relationship is highly significant $\left(N=6, R^{2}=\right.$ $0.93, P=0.0018$ ). There was no relationship between SVL and elevation for males or females $\left(N=8, R^{2}<0.001, P=0.96\right.$, and $N=7, R^{2}=$ $0.035, P=0.69$, respectively; Fig. $3 \mathrm{~B}$ ).

In the field, mean growth rate was $0.0077 \mathrm{~mm} /$ day $( \pm 0.0070 \mathrm{SD}, N=90)$ for males and $0.0097 \mathrm{~mm} /$ day $( \pm 0.0088 \mathrm{SD}, N=$ 11) for females but were not different $\left(F_{1,98}=\right.$ $0.69, P=0.41$; Fig. 4). Field growth rates were not significantly related to body size for either males $\left(N=89, R^{2}=0.009, P=0.37\right)$ or females $\left(N=11, R^{2}=0.28, P=0.093\right)$.

In the laboratory, mean growth rate was $0.0092 \mathrm{~mm} /$ day $( \pm 0.0048 \mathrm{SD}, N=35)$ for males and $0.0097 \mathrm{~mm} /$ day $( \pm 0.0063 \mathrm{SD}, N=$ 26) for females. Growth rates observed in the laboratory were not related to body size for males $(N=35, F=0.030, P=0.86)$ but were related to body size for females (rate $=-0.0011$ SVL $+0.048 ; N=26, F=8.86, P=0.0066)$. There was no difference between growth rates in the field or laboratory or between males and females $\left(F_{3,156}=1.05, P=0.37\right)$.

\section{DisCUSSION}

Although density estimates for adult E. coqui vary across sites (Stewart and Pough, 1983; Woolbright, 1991; Stewart and Woolbright, 1996; Fogarty and Vilella, 2002), estimates of long-term averages from Puerto Rico range from 1-33 adults $/ 100 \mathrm{~m}^{2}$. We found that for all sites surveyed, except for Kalopa and Waipio, mean adult estimates were greater than the highest long-term estimates from Puerto Rico. In fact, we found that adult densities were about three times greater at three of our study sites (around 100 adults $/ 100 \mathrm{~m}^{2}$ ) than the highest long-term estimates from Puerto Rico. Our highest estimates for sampling periods were 133 and 138 adults $/ 100 \mathrm{~m}^{2}$ in Lava Tree and Manuka, respectively, and were higher than the highest estimate for a sampling period in Puerto Rico, 114 adults $/ 100 \mathrm{~m}^{2}$ (Stewart and Woolbright, 1996). Woolbright et al. (2006) similarly suggested that Lava Tree had high adult densities (74-118 adults/100 $\mathrm{m}^{2}$ ).

We found that, averaged over the three years, total E. coqui density across sites ranged from $2,200-50,000$ frogs/ha. At four of the eight study sites, total frog densities were at least 1.7 times 

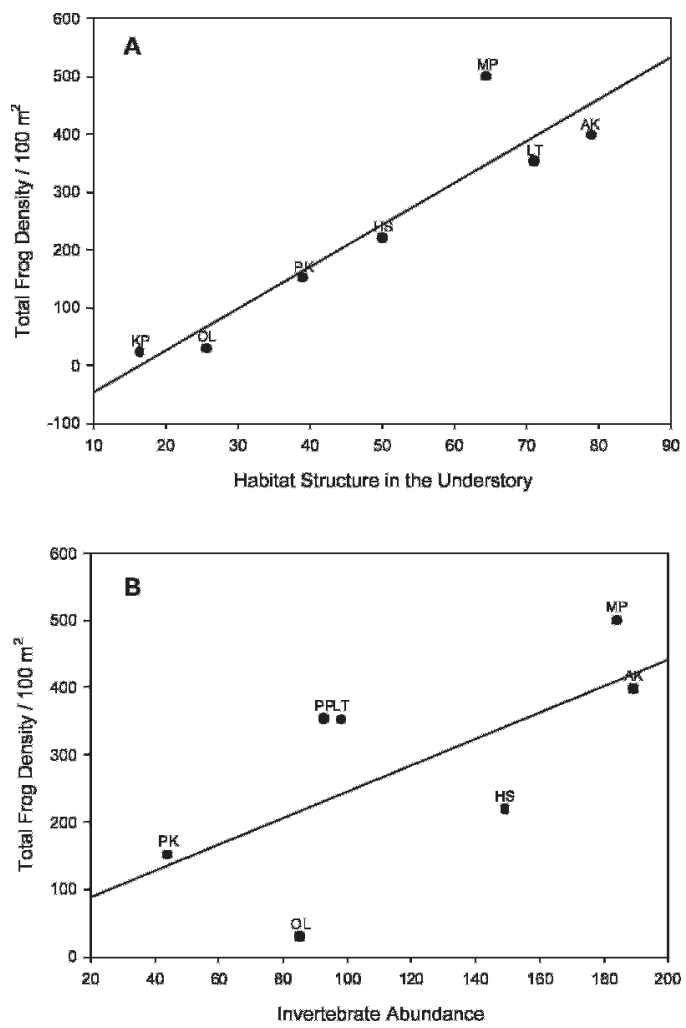

FIG. 2. Mean total frog density/100 $\mathrm{m}^{2}$ (A) and habitat structure in the understory and (B) invertebrate abundance for eight study sites on the Island of Hawaii. Invertebrates were collected at each site in 2004 and frog density is from 2004.

greater (35,000 frogs/ha) than mean long-term estimates for the eastern mountains of Puerto Rico (20,570/frogs ha; elevation 350 m; Stewart and Woolbright 1996). Our highest total density estimate was for Manuka in 2004, where we estimated there were 91,000 frogs/ha. Manuka has been a focus of E. coqui control. There were aerial applications of citric acid in May 2005, October 2005, November 2005, March 2006, and August 2006 and extensive ground treatments. These treatments likely contributed to the decline observed at this location over the study period, even though our plot was intentionally missed by the aerial applications until March 2006. Woolbright et al. (2006) suggested that Lava Tree had similarly high densities $(28,000-$ 89,000 frogs/ha); our highest estimate for Lava Tree was 40,000 frogs/ha.

We used closed capture models with a robust-design to estimate E. coqui population densities. One potential problem with these models is that they assume no losses or gains during annual sampling events (Kendall, 1999). We acknowledge that losses to mortality may have occurred during the 5-9 day sampling events. However, this would result in a negative bias in our abundance estimates, which we consider minimal because of the short time period of our sampling events. In support of the use of these models, which are insensitive to variable capture-recapture rates (e.g., robustdesign models, Pollock, 1982), we observed variability in capture-recapture rates across all plots (both within and across years). Because, in general, we observed low capture-recapture rates across all periods and sampling occasions, we suggest that index methods (e.g., count data) may severely underestimate the abundance of E. coqui.

Our preadult to adult ratios were much lower than those found in Puerto Rico, which have been found to be as high as $15: 1$, with means of $5.3: 1$ (Stewart and Woolbright, 1996). Because preadult activity is so dependent on daily weather conditions, it can be difficult to speculate on the importance of this ratio. However, we surveyed for a total of 120 nights

TABLE 3. Mean snout-vent length (SVL) in mm ( \pm SD) and sample size $(n)$ recorded from Eleutherodactylus coqui on the Island of Hawaii. Males were identified by having vocal sacs and females were identified if gravid. For all study sites, individuals were collected over three years, except for Kalopa State Park (KP) and Paradise Park (PP).

\begin{tabular}{|c|c|c|c|c|c|c|c|}
\hline \multirow[b]{2}{*}{ Site } & \multicolumn{3}{|c|}{ Male } & \multicolumn{3}{|c|}{ Female } & \multirow{2}{*}{$\begin{array}{l}\text { Maximum } \\
\text { SVL (mm) }\end{array}$} \\
\hline & SVL (mm) & SD & $n$ & SVL (mm) & SD & $n$ & \\
\hline$\overline{\mathrm{AK}}$ & $29.7^{\mathrm{AB}^{*}}$ & 2.10 & 76 & 38.3 & 1.83 & 11 & 43.2 \\
\hline HS & $29.2^{\mathrm{BC}}$ & 2.25 & 342 & 35.7 & 2.18 & 31 & 41.4 \\
\hline $\mathrm{KP}$ & $28.7^{C}$ & 2.09 & 60 & 34.3 & 1.31 & 6 & 36.2 \\
\hline LT & $27.7^{\mathrm{D}}$ & 2.02 & 254 & 34.2 & 3.50 & 30 & 42.5 \\
\hline MP & $29.1^{C}$ & 1.86 & 182 & 32.0 & 0.82 & 4 & 39.6 \\
\hline $\mathrm{OL}$ & $30.3^{\mathrm{A}}$ & 2.41 & 137 & 37.8 & 0.28 & 2 & 48.5 \\
\hline PK & $29.8^{\mathrm{AB}}$ & 2.29 & 208 & 34.4 & 2.87 & 16 & 41.1 \\
\hline $\mathrm{PP}$ & $28.9^{C}$ & 2.27 & 60 & - & - & - & 41.6 \\
\hline
\end{tabular}

*Different letters show significant differences across sites $(P<0.05)$.

Note: Statistical analyses were not conducted using females because of sample size limitations. 

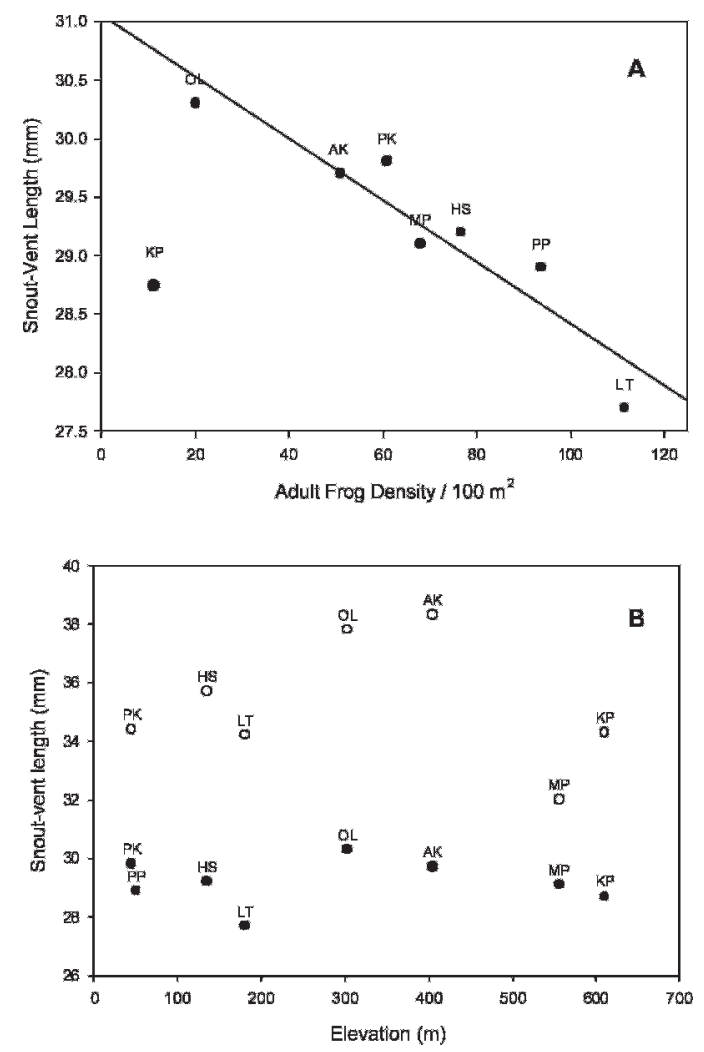

FIG. 3. Mean snout-vent length (SVL) (A) of adult males and adult density of Eleutherodactylus coqui averaged across years, 2004-2006, for eight study sites on the Island of Hawaii. The regression line represents the relationship for all sites except Kalopa State Park, and (B) of male and female E. coqui and elevation averaged across years, 2004-2006, for eight study sites on the Island of Hawaii. Males are closed circles and females are open circles.

and on only five occasions was our ratio above $5.3: 1$. Woolbright et al. (2006) similarly found preadult to adult ratios in Hawaii were generally lower than those in Puerto Rico. There are several potential explanations for this pattern. It could be that, in Hawaii, preadults are significantly harder to observe because of their behavior of remaining closer to the forest floor than adults (Beard, 2007) and potentially hiding in a'a lava (i.e., rocks; Woolbright et al., 2006). Alternatively, reproductive success or survivorship to hatchling, juvenile, or subadult stages could be lower in Hawaii. It would be important to test these hypotheses in future studies.

High E. coqui densities in Hawaii may threaten endemic invertebrates and associated ecosystem functioning (Beard and Pitt, 2005). Research suggests that each frog, on average, consumes 7.6 prey items per night (Beard, 2007); and thus, with densities as high as 91,000 frogs/

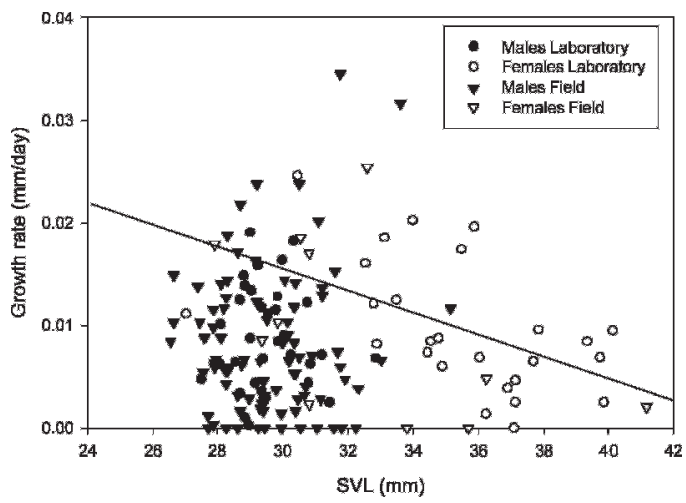

FIG. 4. Relationship between growth rates since last capture of male and female Eleutherodactylus coqui and snout-vent length (SVL) in the field and in the laboratory. Points are plotted with respect to the $\mathrm{x}$ axis at the arithmetic mean of initial SVL and final SVL. The regression line for females in the laboratory is shown.

ha, E. coqui could be consuming 690,000 invertebrates/ha/night. In addition, research suggests that $E$. coqui can reduce prey abundance (Sin et al., 2008), and we found that the relationship between $E$. coqui and invertebrate abundances across sites was positive, although not significant by our criteria $(P=0.10)$. However, we also found support for the idea that E. coqui are not prey limited; their growth rates did not differ in the laboratory and field. There is other evidence that suggests that prey are not limiting at least at some sites. For example, E. coqui have been found to avoid lesspreferred prey at some sites, even though they consume these prey at sites lacking preferred prey (Beard, 2007). Based on the available evidence, support for the hypothesis that $E$. coqui are prey limited in Hawaii is weak.

The primary factor thought to limit E. coqui in Puerto Rico is the amount of available nest and retreat sites (Stewart and Pough 1983; Woolbright, 1996). Consequently, areas with more dense undergrowth are thought to support greater densities (Fogarty and Vilella, 2001). We found a highly significant, positive relationship between the amount of understory habitat structure and E. coqui density in Hawaii. The relatively low density of E. coqui at Kalopa and Waipio appears to result from the low amount of understory structure at those locations. This suggests that E. coqui will attain higher densities where there is more understory structure and that reducing understory structure could reduce E. coqui populations.

Any management practice aimed at removing understory habitat structure to reduce $E$. coqui densities should be conducted in a way that 
does not harm the native invertebrate community. Most of the study sites where E. coqui has invaded are dominated by nonnative plants in the canopy and understory. The best management practice would be to remove the nonnative plant species and restore these forests with native species with low amounts of understory structure. This could result in both reduced $E$. coqui densities and native forest restoration. In addition, by removing nonnative plants, this management practice may restore native invertebrates to these communities.

A study from Puerto Rico found a negative relationship between growth rate and SVL for both males and females in the field and not in the laboratory (Woolbright, 1989). We only uncovered this relationship for females in the laboratory. It is hypothesized that this relationship starts when frogs reach sexual maturity and is driven by energetic constraints (Woolbright, 1989). Results from Puerto Rico suggest that, when males are no longer constrained energetically (i.e., in a laboratory), they can grow at a much faster rate at a particular size (Woolbright, 1989). However, we found that male growth rates in the field and laboratory were similar. It is unclear why male frogs in Hawaii may not be experiencing the energetic costs of reproduction that they experience in Puerto Rico. Potential explanations include that frogs in Hawaii are younger than those studied in Puerto Rico, which might be expected for newly invaded sites. Alternatively, male frogs in Hawaii may have less need to defend nest sites from competitors and predators or less need to invest in calling. Future studies could investigate potential mechanisms driving this pattern.

It was difficult to directly compare growth rates of males in the field in Hawaii and Puerto Rico because the study conducted in Puerto Rico found a negative relationship between growth rate and SVL, and the majority of our males were below the minimum size studied (Woolbright, 1989). However, using the equation for the relationship between SVL and growth rates presented in Woolbright (1989), we found that male frogs in Hawaii were growing slower (around $0.008 \mathrm{~mm} /$ day) than would be predicted for similar-sized frogs in Puerto Rico (around $0.02 \mathrm{~mm} /$ day). We did not encounter similar problems comparing female growth rates in the field between the two ranges and found that females of similar size (on average $35 \mathrm{~mm}$ ) grew slower in Hawaii (around $0.01 \mathrm{~mm} /$ day) than those in Puerto Rico (0.07 mm/day; Woolbright, 1989). Caution should be used when interpreting these results because Puerto Rico data were collected in one study site, the eastern mountains, whereas our data were collected across the Island of Hawaii.

Body size of $E$. coqui has been found to increase with increasing elevation (Narins and Smith, 1986), and density of E. coqui has been found to decrease with increasing elevation in Puerto Rico (Stewart and Woolbright 1996). We investigated these patterns and did not find these relationships. There may be confounding factors that make observations of these patterns difficult at this time. The most important of these may be that many of these populations are newly established and have been reproductive for only a few years (Woolbright et al., 2006). This would limit the ability of E. coqui to respond to local site conditions, such as temperature, which may be driving these patterns (Velo-Antón et al., 2007). However, the above two relationships also suggest that $E$. coqui has smaller SVL where E. coqui density is greater. We did find a negative relationship between $E$. coqui density and SVL (with Kalopa removed from the analysis). If we assume that productivity is similar across sites, this relationship suggests that E. coqui are competing for resources. However, because we cannot make this assumption, it is difficult to determine what is driving this pattern. It simply may be that, at sites with higher productivity, there are greater E. coqui densities, and E. coqui are able to reproduce at a smaller size. Further study is needed to determine why SVL may be smaller where densities are higher in Hawaii.

The use of mark-recapture methods for estimating the abundance of $E$. coqui is common in the literature (Fogarty and Vilella, 2001, 2002; Woolbright, 2005), and many of these markrecapture studies have used toe clips as the means for marking individuals (Woolbright, 1989, 1996, 2005; Woolbright et al., 2006). We found that the number of toes clipped negatively affected recapture probabilities at three of eight study sites and survival estimates at one of six study sites. Thus, caution should be exercised when using toe clips to mark E. coqui, especially in Puerto Rico, where montane populations are declining (Burrowes et al., 2004). If toe clips are used, our results suggest that no more than one toe be clipped per frog. Other marking methods, including the use of fluorescent pigments, have been used for this species (e.g., Fogarty and Vilella, 2001, 2002). We suggest that future research on this species compare survival and recapture probability estimates using various marking methods.

Acknowledgments.-Funding was provided by the U.S. Fish and Wildlife Service, the Jack Berryman Institute, and the Hawaii Department of Land and Natural Resources (Hawaii Inva- 
sive Species Council). We thank L. L. Woolbright for methodological instruction; A. Huff, N. Huff, K. Juanarajs, B. Carter, J. Verlinde, M. Higashi, and R. McGuire for field assistance; and J. Gibson for graphics assistance. Research was conducted under IACUC protocols 1145 and 1251 and the following state of Hawaii permits: Injurious Wildlife Export, Research Access, and NARS Special Use.

\section{Literature Cited}

BEARD, K. H. 2001. The Ecological Roles of a Terrestrial Frog, Eleutherodactylus coqui (Thomas), in the Nutrient Cycles of a Subtropical Wet Forest in Puerto Rico. Unpubl. PhD diss., Yale University, New Haven, CT.

2007. Diet of the invasive frog, Eleutherodactylus coqui, in Hawaii. Copeia 2007:281-291.

Beard, K. H., And W. C. PItT. 2005. Potential consequences of the coqui frog invasion in Hawaii. Diversity and Distributions 11:427-433.

Bradford, M. J., J. Korman, and P. S. Higgins. 2005. Using confidence intervals to estimate the response of salmon populations (Oncorhynchus spp.) to experimental habitat alterations. Canadian Journal of Fisheries and Aquatic Sciences 62:2716-2726.

Burnham, K. P., And D. R. Anderson. 1998. Model Selection and Inference: A Practical InformationTheoretic Approach. Springer-Verlag, New York.

Burrowes, P., R. Joglar, and D. Green. 2004. Potential causes for amphibian declines in Puerto Rico. Herpetologica 60:141-154.

Fogarty, J. H., AND F. J. Vilella. 2001. Evaluating methodologies to survey Eleutherodactylus frogs in montane forests of Puerto Rico. Wildlife Society Bulletin 29:948-955.

- 2002. Population dynamics of Eleutherodactylus coqui in Cordillera Forest reserves of Puerto Rico. Journal of Herpetology 36:193-201.

Franklin, A. B., R. J. Gutiérrez, J. D. Nichols, M. E. Seamans, G. C. White, G. S. Zimmerman, J. E. Hines, T. E. Munton, W. S. LaHaye, J. A. Blakesley, G. N. Steger, B. R. Noon, D. W. H. Shaw, J. J. Keane, T. L. McDonald, And S. Britting. 2004. Population dynamics of the California Spotted Owl (Strix occidentalis occidentalis): a meta-analysis. Ornithological Monographs 54:1-55.

Kendall, W. L. 1999. Robustness of closed capturerecapture methods to violations of the closure assumption. Ecology 80:2517-2525.

Kendall, W. L., J. D. Nichols, and J. E. Hines. 1997. Estimating temporary emigration using capturerecapture data with Pollock's robust design. Ecology 78:563-578.

Kraus, F., AND E. W. CAMpbell. 2002. Human-mediated escalation of a formerly eradicable problem: the invasion of Caribbean frogs in the Hawaiian Islands. Biological Invasions 4:327-332.

Kraus, F., E. W. Campbell, A. Allison, and T. Pratt. 1999. Eleutherodactylus frog introductions to Hawaii. Herpetological Review 30:21-25.
NARINS, P. M., AND S. L. SMITH. 1986. Clinal variation in anuran advertisement calls: basis for acoustic isolation? Behavioral Ecology and Sociobiology 19:135-141.

NuDDS, T. 1977. Quantifying the vegetative structure of wildlife cover. Wildlife Society Bulletin 5:113-117.

Nullet, D., AND M. SANDERSON. 1993. Radiation and energy balances and air temperatures. In $\mathrm{M}$. Sanderson (ed.), Prevailing Trade Winds: Weather and Climate in Hawaii, pp. 37-55. University of Hawaii Press, Honolulu.

Pollock, K. H. 1982. A capture-recapture design robust to unequal probability of capture. Journal of Wildlife Management 46:757-760.

PrICE, S. 1983. Climate. In R. W. Armstrong (ed.), Atlas of Hawaii, pp. 59-66. University of Hawaii Press, Honolulu.

Sin, H., K. H. Beard, and W. C. Pitt. 2008. An invasive frog, Eleutherodactylus coqui, has top-down effects on new leaf production and leaf litter decomposition rates through nutrient cycling in Hawaii. Biological Invasions 10:335-345.

Stewart, M. M., and F. H. Pough. 1983. Population density of tropical forest frogs: relation to retreat sites. Nature 221:570-572.

Stewart, M. M., and L. L. Woolbright. 1996. Amphibians. In D. P. Reagan and R. B. Waide (eds.), The Food Web of a Tropical Rain Forest, pp. 363-398. University of Chicago Press, Chicago.

Trusdell, F. A., E. W. Wolfe, ANd J. Morris. 2005. Digital Database of the Geologic Map of the Island of Hawai'i. U.S. Geological Survey Data Series 144. Available at: http://pubs.usgs.gov/ds/2005/144/.

Velo-Antón, G., P. A. Burrowes, R. Joglar, I. Martínez-Solano, K. H. Beard, and G. Parra-Olea. 2007. Phylogenetic study of Eleutherodactylus coqui (Anura: Leptodactylidae) reveals deep genetic fragmentation in Puerto Rico and pinpoints origins of Hawaiian populations. Molecular Phylogenetics and Evolution 45:716-728.

White, G. C., And K. P. Burnham. 1999. Program MARK: survival estimation from populations of marked animals. Bird Study 46:120-138.

Woolbright, L. L. 1989. Sexual dimorphism in Eleutherodactylus coqui: selection pressures and growth rates. Herpetologica 45:68-74.

. 1991. The impact of Hurricane Hugo on forest frogs in Puerto Rico. Biotropica 23:462-467.

—. 1996. Disturbance influences long-term population patterns in the Puerto Rican frog, Eleutherodactylus coqui (Anura: Leptodactylidae). Biotropica 28:493-501.

—_. 2005. A plot-based system of collecting population information on terrestrial breeding frogs. Herpetological Review 36:139-142.

Woolbright, L. L., A. H. Hara, C. M. Jacobsen, W. J. Mautz, And F. L. Benevides. 2006. Population densities of the coqui, Eleutherodactylus coqui (Anura: Leptodactylidae) in newly invaded Hawaii and in native Puerto Rico. Journal of Herpetology 40:122-126.

Accepted: 17 March 2008. 
ApPendix 1. The top four models, including AICc, Delta AIC, AIC weights, model likelihood, number of parameters, and deviance, for each of the eight study sites from Eleutherodactylus coqui mark-recapture analyses on the Island of Hawaii. Abundance and survival was estimated using robust-design models (Huggins closed capture) in Akaka Falls, Humane Society, Lava Tree, Manuka Park, Puainako, and Waipio plots, and Huggins closed capture models were used in Paradise Park (2004) and Kalopa plots (2005 and 2006).

\begin{tabular}{cccccccc}
\hline \hline & & & Delta & AICc & Model & Num. \\
Site & Model & AIC & AIC & Weights & Likelihood & Par & Deviance \\
\hline
\end{tabular}

Akaka Falls State Park (AK)

$\mathrm{S}$ (Toe) $\gamma^{\prime}=\gamma^{\prime \prime} p\left(\mathrm{t}^{*}\right.$ session $)=c\left(\mathrm{t}^{*}\right.$ session $)$, $c+$ toe
$(.) \gamma^{\prime}=\gamma^{\prime \prime} p\left(\mathrm{t}^{*}\right.$ session $)=c\left(\mathrm{t}^{*}\right.$ session $)$,

$c+$ toe

$2,248.68$

S (.) $\gamma^{\prime}=\gamma^{\prime \prime} p\left(\mathrm{t}^{*}\right.$ session $)=c\left(\mathrm{t}^{*}\right.$ session $)$
$\mathrm{S}(\mathrm{t}) \gamma^{\prime}=\gamma^{\prime \prime} p\left(\mathrm{t}^{*}\right.$ session $)=c\left(\mathrm{t}^{*}\right.$ session $)$

$2,254.11$

0

0.8534

1

23

$2,200.43$

$2,255.13$

5.43

0.0561

6.46

0.0337

0.0661

0.0397

$22 \quad 2,208.06$

ane Society (HS)

$\mathrm{S}$ (Toe) $\gamma^{\prime}=\gamma^{\prime \prime} p\left(\mathrm{t}^{*}\right.$ session $)=c\left(\mathrm{t}^{*}\right.$ session $)$, $c+$ toe

$2,256.31 \quad 7.63$

0.0188

0.0221

$2,206.89$

$2,208.06$

S (.) $\gamma^{\prime}=\gamma^{\prime \prime} p\left(\mathrm{t}^{*}\right.$ session $)=c\left(\mathrm{t}^{*}\right.$ session $)$, $c+$ toe

$4,193.78$

0

0.8902

1

22

$4,148.74$

$\mathrm{S}(\mathrm{t}) \gamma^{\prime}=\gamma^{\prime \prime} p\left(\mathrm{t}^{*}\right.$ session $)=c\left(\mathrm{t}^{*}\right.$ session $)$, $c+$ toe

$4,198.97$

5.19

0.0665

0.0747

20

$4,158.11$

$\mathrm{S}(\mathrm{t}) \gamma^{\prime}=\gamma^{\prime \prime} p\left(\mathrm{t}^{*}\right.$ session $)=c\left(\mathrm{t}^{*}\right.$ session $)$

$4,201.05$

7.28

0.0234

0.0263

21

$4,158.11$

$4,202.00$

8.22

0.0146

0.0164

$4,161.14$

Lava Tree State Park (LT)

S (.) $\gamma^{\prime}=\gamma^{\prime \prime} p\left(\mathrm{t}^{*}\right.$ session $)=c\left(\mathrm{t}^{*}\right.$ session $)$, $c+$ toe

$4,192.49$

0

0.5926

1

21

$4,149.64$

(Toe) $\gamma^{\prime}=\gamma^{\prime \prime} p\left(\mathrm{t}^{*}\right.$ session $)=c\left(\mathrm{t}^{*}\right.$ session $)$ $c+$ toe

$4,193.73$

0.3192

0.5386

22

$4,148.80$

$c+$ toe

$4,196.62$

4.13

0.0752

0.1269

23

$4,149.60$

$\mathrm{S}(\mathrm{t}) \gamma^{\prime}=\gamma^{\prime \prime} p\left(\mathrm{t}^{*}\right.$ session $)=c\left(\mathrm{t}^{*}\right.$ session $)$

$4,201.15$

8.66

0.0078

0.0131

$4,156.22$

Manuka Natural Area Reserve (State Park) (MP)

$\mathrm{S}$ (Toe) $\gamma^{\prime}=\gamma^{\prime \prime} p\left(\mathrm{t}^{*}\right.$ session $)=c\left(\mathrm{t}^{*}\right.$ session $)$, $c+$ toe

$1,673.67$

0

0.9566

1

$1,631.59$

S (.) $\gamma^{\prime}=\gamma^{\prime \prime} p\left(\mathrm{t}^{*}\right.$ session $)=c\left(\mathrm{t}^{*}\right.$ session $)$ $c+$ toe

$1,680.66$

6.99

0.0291

0.0304

19

$1,640.78$

$\mathrm{S}(\mathrm{t}) \gamma^{\prime}=\gamma^{\prime \prime} p\left(\mathrm{t}^{*}\right.$ session $)=c\left(\mathrm{t}^{*}\right.$ session $)$, $c+$ toe

$1,682.86$

9.19

0.0097

0.0101

$20 \quad 1,640.78$

$\mathrm{S}(\mathrm{t}) \gamma^{\prime}=\gamma^{\prime \prime} p\left(\mathrm{t}^{*}\right.$ session $)=c\left(\mathrm{t}^{*}\right.$ session $)$

$1,684.34$

10.66

0.0046

0.0048

$19 \quad 1,644.45$

Puainako/Safeway (PK)

$\mathrm{S}$ (Toe) $\gamma^{\prime}=\gamma^{\prime \prime} p\left(\mathrm{t}^{*}\right.$ session $)=c\left(\mathrm{t}^{*}\right.$ session $)$,

$$
c+\text { toe }
$$

S (.) $\gamma^{\prime}=\gamma^{\prime \prime} p\left(\mathrm{t}^{*}\right.$ session $)=c\left(\mathrm{t}^{*}\right.$ session $)$, $c+$ toe

$\begin{array}{llllll}2,721.39 & 0 & 0.4973 & 1 & 25 & 2,669.16 \\ & & & & & \\ 2,722.23 & 0.84 & 0.3268 & 0.6571 & 24 & 2,672.18 \\ & & & & & \\ 2,724.41 & 3.01 & 0.1101 & 0.2215 & 25 & 2,672.18 \\ 2,726.82 & 5.43 & 0.0329 & 0.0662 & 24 & 2,676.77\end{array}$

$\mathrm{S}(\mathrm{t}) \gamma^{\prime}=\gamma^{\prime \prime} p\left(\mathrm{t}^{*}\right.$ session $)=c\left(\mathrm{t}^{*}\right.$ session $)$, $c+$ toe

$2,726.82$

5.43

0.0662

$2,676.77$

Waipio Overlook (OL)

$\left\{S(.) \gamma^{\prime}=\gamma^{\prime \prime} p\left(t^{*}\right.\right.$ session $)=c\left(t^{*}\right.$ session $)$, $c+$ toe
(Toe) $\gamma^{\prime}=\gamma^{\prime \prime} p\left(\mathrm{t}^{*}\right.$ session $)=c\left(\mathrm{t}^{*}\right.$ session $)$,

S (Toe) $\gamma^{\prime}=\gamma^{\prime \prime} p\left(\mathrm{t}^{*}\right.$ session $)=c\left(\mathrm{t}^{*}\right.$ session $)$,
$c+$ toe

$\left\{\mathrm{S}(\mathrm{t}) \gamma^{\prime}=\gamma^{\prime \prime} p\left(\mathrm{t}^{*}\right.\right.$ session $)=c\left(\mathrm{t}^{*}\right.$ session $)$, $c+$ toe

$1,126.91$

0

0.4575

1

18

$1,088.54$

$1,127.25$

0.34

0.3854

0.8424

$19 \quad 1,086.61$

$\begin{array}{lll}1,129.05 & 2.14 & 0.1570\end{array}$

0.3432

$19 \quad 1,088.41$

$\left\{\mathrm{S}(\mathrm{t}) \gamma^{\prime}=\gamma^{\prime \prime} p\left(\mathrm{t}^{*}\right.\right.$ session $)=c\left(\mathrm{t}^{*}\right.$ session $)$

$1,146.88$

19.97

0.0000

0

$18 \quad 1,108.51$

Huggins Closed Capture

Paradise Park 2004 (PP)

\begin{tabular}{lllllll}
$p\left(\mathrm{t}^{*}\right.$ session $)=c\left(\mathrm{t}^{*}\right.$ session $)$ & $1,946.13$ & 0 & 0.5204 & 1 & 5 & $1,936.10$ \\
$p\left(\mathrm{t}^{*}\right.$ session $)=c\left(\mathrm{t}^{*}\right.$ session $), c+$ toe & $1,947.55$ & 1.43 & 0.2550 & 0.4902 & 6 & $1,935.51$ \\
\hline
\end{tabular}


ApPENDix 1. Continued.

\begin{tabular}{|c|c|c|c|c|c|c|}
\hline Model & $\mathrm{AICc}$ & $\begin{array}{l}\text { Delta } \\
\text { AICc }\end{array}$ & $\begin{array}{c}\text { AICc } \\
\text { Weights }\end{array}$ & $\begin{array}{c}\text { Model } \\
\text { Likelihood }\end{array}$ & $\begin{array}{l}\text { Num. } \\
\text { Par }\end{array}$ & Deviance \\
\hline$p\left(\mathrm{t}^{*}\right.$ session $)=c\left(\mathrm{t}^{*}\right.$ session $), c+$ constant & $1,948.11$ & 1.99 & 0.1926 & 0.3702 & 6 & $1,936.07$ \\
\hline$p\left(\mathrm{t}^{*}\right.$ session $) c\left(\mathrm{t}^{*}\right.$ session $)$ & $1,953.32$ & 7.20 & 0.0142 & 0.0273 & 9 & $1,935.23$ \\
\hline \multicolumn{7}{|l|}{ Kalopa State Park 2005 (KP) } \\
\hline$p() c.()$. & 130.22 & 0 & 0.7047 & 1 & 2 & 126.15 \\
\hline$p()$.$c (toe)$ & 132.03 & 1.81 & 0.2847 & 0.404 & 3 & 125.89 \\
\hline$p(\mathrm{t})=c(\mathrm{t})$ & 139.73 & 9.51 & 0.0061 & 0.0086 & 8 & 122.82 \\
\hline$p(\mathrm{t})=c(\mathrm{t})\} c+$ toe & 141.15 & 10.93 & 0.0030 & 0.0042 & 9 & 122.01 \\
\hline \multicolumn{7}{|l|}{ Kalopa State Park 2006 (KP) } \\
\hline$p()$.$c (toe)$ & 350.71 & 0 & 0.5161 & 1 & 3 & 344.62 \\
\hline$p() c.()$. & 350.96 & 0.25 & 0.4546 & 0.8807 & 2 & 346.92 \\
\hline$p(\mathrm{t})=c(\mathrm{t}), c+$ constant & 357.97 & 7.26 & 0.0137 & 0.0264 & 6 & 345.66 \\
\hline$p(\mathrm{t})=c(\mathrm{t})$ & 358.05 & 7.35 & 0.0131 & 0.0254 & 5 & 347.83 \\
\hline
\end{tabular}

Note: toe corresponds to the number of toe clips, which was modeled as an individual covariate; session corresponds to the primary sampling occasion (year); $t$ corresponds to secondary sampling occasion (day); and (.) corresponds to models where parameters did not vary through time. 